\title{
Occurrence and environmental implications of pharmaceuticals in Chinese municipal sewage sludge
}

\author{
Yongshan Chen ${ }^{\mathrm{a}, \mathrm{b}, *}$, Gang Yu ${ }^{\mathrm{b}}$, Qiming Cao ${ }^{\mathrm{c}}$, Haibo Zhang ${ }^{\mathrm{d}}$, Qiaoying Lin ${ }^{\mathrm{a}}$, Youwei Hong ${ }^{\mathrm{a}}$ \\ ${ }^{a}$ Key Laboratory of Urban Environment and Health, Institute of Urban Environment, Chinese Academy of Sciences, Xiamen 361021, PR China \\ ${ }^{\mathrm{b}}$ School of Environment, THU-VEOLIA Joint Research Center for Advanced Environmental Technology, Tsinghua University, Beijing 100084, PR China \\ ' School of Resources and Environment, University of Electronic Science and Technology of China, Chengdu 611731, PR China \\ ${ }^{\mathrm{d}}$ Yantai Institute of Coastal Zone Research, Chinese Academy of Sciences, Yantai 264003, PR China
}

\section{H I G H L I G H T S}

- Pharmaceutical residuals were analyzed for sludge samples from 45 sewage treatment plants in China.

- Fluoroquinolone and tetracycline were the dominant antibiotics.

- Other pharmaceuticals such as ketoprofen and ibuprofen also in significant presence.

- Poor agreement found between the detected and predicted concentrations.

\section{A R T I C L E I N F O}

\section{Article history:}

Received 15 February 2013

Received in revised form 31 May 2013

Accepted 6 June 2013

Available online 1 July 2013

\section{Keywords:}

Pharmaceuticals

Sewage sludge

Occurrence

Environmental implications

\begin{abstract}
A B S T R A C T
The presence of pharmaceuticals in aquatic environment has become a topic of concern because of their potential adverse effects on human health and wildlife species. A total of 45 dewatered sewage sludge samples were collected throughout China and analyzed for 30 commonly consumed pharmaceutical residues. Ofloxacin was found to be the dominant contaminant with concentrations up to $24760 \mu \mathrm{g} \mathrm{kg}^{-1}$, followed by oxytetracycline $\left(5280 \mu \mathrm{g} \mathrm{kg}{ }^{-1}\right)$, norfloxacin $\left(5280 \mu \mathrm{g} \mathrm{kg}^{-1}\right)$ and ketoprofen $\left(4458 \mu \mathrm{g} \mathrm{kg}^{-1}\right)$. The concentration of pharmaceutical residues varied greatly depending on the operation conditions of wastewater treatment plants and sampling locations. Poor agreement was found between the predicted (calculation based on the annual consumption and coefficient of sludge water partition) and detected concentrations of the pharmaceuticals indicating that the occurrence of pharmaceutical residues was affected by various factors such as loading rates, sewage properties and the chemical properties such as the contribution from polar groups. National wide fate and ecotoxicity study is required for the development of control strategies.
\end{abstract}

(ㄷ) 2013 Elsevier Ltd. All rights reserved.

\section{Introduction}

Pharmaceuticals as emerging organic pollutants have received increasing attention by the scientific community in recent years, due to their frequent occurrence in the environment and associated health risks (Ellis, 2006; Kümmerer, 2009). These contaminants are observed at concentrations of several nanograms per liter in the aquatic environment as a result of human and animal activities (Kolpin et al., 2002; Kaplan, 2012). Although found in trace levels, some therapeutic compounds such as synthetic sex hormones and antibiotics have been found to cause adverse effects on aquatic organisms (Kristiansson et al., 2011; Lee et al., 2012). In

\footnotetext{
* Corresponding author. Address: 1799 Jimei Road, Xiamen 361021, PR China. Tel./fax: +865926190562.

E-mail address: yschen@iue.ac.cn (Y. Chen).
}

addition, pharmaceuticals may accumulate and cause irreversible changes in wildlife and humans (Daughton and Ternes, 1999).

Most pharmaceuticals are likely to persist in wastewater systems due to their hydrophilic properties. The polar functional groups (carboxylic moieties, aldehydes and amines) of these compounds may interact with suspended organic materials and lead to their high concentration in sewage sludge (Ternes et al., 2004; Carballa et al., 2008). Due to the lack of reliable analytical methods, most previous studies have focused on the water phase of pharmaceuticals in sewage (Ort et al., 2010; Bailly et al., 2013). In fact, most biological wastewater treatment plants have high removal efficiencies for pharmaceuticals resulting from the sorption and sedimentation of these products into the sludge (Jelic et al., 2011; Jia et al., 2012). The majority of pharmaceuticals in sludge are likely to be discharged into terrestrial environment after sludge disposal, causing serious environmental problems in some cases (Martín et al., 2012a,b). Agricultural use and land-fill are two major 
sludge disposal practices worldwide (Kelessidis and Stasinakis, 2012), which may contaminate food chain and water supply. The presence of pharmaceuticals in sewage sludge therefore becomes an important issue in China which produces more than 10 million tonnes of dry sludge every year with more than $70 \%$ of which are landfilled or used in the agricultural sector (40\%) (Chen et al., 2012a).

Previous studies have shown that the level of pharmaceuticals varied greatly in the sewage sludge ranging from several micrograms per kilogram to milligrams per kilogram depending on the sampling point and properties of the compounds (Miao et al., 2005; Nieto et al., 2007; McClellan and Halden, 2010). Among all studied pharmaceuticals, antibiotics have been on the priority list due to the antibiotic-resistance genes found in bacteria (Gao et al., 2012). Research shows that tetracyclines, fluoroquinolones, sulfonamides and macrolides are the dominant antibiotic classes presented in sewage sludge samples in the United States (McClellan and Halden, 2010), Canada (Miao et al., 2005), Spain (Nieto et al., 2007; Radjenović et al., 2009), Germany (Ternes et al., 2005), Switzerland (Göbel et al., 2005) and China (Yu et al., 2011; Jia et al., 2012). However, most recent investigations on pharmaceuticals in sewage sludges have been limited to the development of analytical methods, or often restricted to one sewage treatment plant (Nieto et al., 2007; Yu et al., 2011), therefore, providing little information on the occurrence of pharmaceuticals in sewage sludge. Pharmaceuticals other than antibiotics should also be studied because of their high concentrations and potential adverse effects on human health (Williams and Brooks, 2012). Therefore, the present study was designed to investigate 30 different pharmaceutical compounds of therapeutic classes in sewage sludge samples collected from wastewater treatment plants across 13 provinces (20 cities) in China. The national load of pharmaceutical products discharged into the environment was also estimated.

\section{Materials and methods}

\subsection{Chemicals and standards}

The analytical standards were obtained from Sigma-Aldrich Corp., (St. Louis, MO). The internal standards of mecoprop-3d, atrazine-5d, chloramphenicol-5d, N,N-diethyl-meta-toluamide-7d (DEET-7d), ofloxacin-d8, and enythromycin- ${ }^{13} \mathrm{C} \& \mathrm{~d} 4$ were purchased from Dr. Ehrenstorfer GmbH (Augsburg, Germany). ${ }^{13} \mathrm{C}-$ phenacetin was obtained from Sigma-Aldrich and gemfibrozil-6d from Toronto Research Chemicals Inc., (Toronto, Canada). HPLC grade methanol and formic acid were provided by Thermo Fisher (Hampton, $\mathrm{NH}$ ) and analytical grade citric acid-monohydrate and sodium phosphate-dibasic anhydrous by Sinopharm Chemical Reagent Co., Ltd., Shanghai, China. Ultra-pure water was prepared with a Milli-Q water purification system (Millipore, Billerica, MA). All the pharmaceutical compounds were dissolved in methanol and stored in a freezer at $4{ }^{\circ} \mathrm{C}$. Working solutions were prepared immediately before use by diluting the stock solutions.

Oasis HLB cartridges $(6 \mathrm{~mL} / 500 \mathrm{mg})$ were purchased from Waters Corp., Milford, MA, glass microfiber filters (GF/F) from Whatman Ltd., (Maidstone, Kent, UK) and syringe-driven filters (PTFE) from Millipore, Billerica, MA.

\subsection{Sample collection}

A total of 45 sewage sludge samples were collected from 20 cities in 13 provinces of China (Fig. 1). More information regarding the wastewater treatment plants is given in the Supplemental material (Table S2). Sewage sludge samples were collected directly from dewatering machines in the sewage treatment plants. Five discrete samples were collected from each wastewater treatment plant and then mixed together to get a composite one. About $500 \mathrm{~g}$ sludge from each final sample was taken by the quadripartite method and transported to the laboratory and stored at $-20^{\circ} \mathrm{C}$ prior to analysis. To assess the sorption behaviors of pharmaceutical products present in sewage sludge, wastewater samples were also collected from 7 sewage treatment plants located in Beijing. Wastewater samples (2 L in duplicates) were collected in prewashed amber glass bottles using the grab sampling technique and transported to the laboratory immediately. The samples were filtered through glass microfiber filters ( $\mathrm{GF} / \mathrm{F}$, Whatman) to remove particulate matters and stored at $4{ }^{\circ} \mathrm{C}$ before the extraction of pharmaceuticals.

\subsection{Sample preparation}

Sludge samples were subjected to pressurized liquid extraction (PLE) method following the procedures as described by Nieto et al. (2007) and Chen et al. (2012b). Briefly, the sludge was homogenized, frozen, lyophilized and passed through a $0.45 \mathrm{~mm}$ sieve before spiking with the internal standards. Samples were extracted with methanol/EDTA-Mcllvaine buffer (50/50, v/v) using accelerated solvent extraction system (PLE2000) equipped with $22 \mathrm{~mL}$ capacity of stainless-steel cells. The extract was diluted to $500 \mathrm{~mL}$ with Mili-Q water and then cleaned up. Each sample was extracted with Oasis HLB cartridges $(500 \mathrm{mg} / 6 \mathrm{~mL}$ ) and the eluate was concentrated and filtered through a $0.20 \mu \mathrm{m}$ PTFE syringe filter.

Wastewater samples $(500 \mathrm{~mL})$ were filtered and spiked with internal standards and then extracted using SPE method. The detailed information on SPE method for sewage sludge preparation and wastewater extraction was given by Chen et al. (2012b,c).

\subsection{HPLC and MS-MS system}

The pharmaceutical residues were separated and quantified using high-performance liquid chromatography (HPLC: Ultimate 3000, Dionex, Sunnyvale, CA) followed by electrospray ionization and tandem mass spectrometry (ESI-MS/MS, API3200, AB Sciex, Framingham, MA). ESI-MS/MS parameters such as declustering potential (DP) and collision energy (CE) for each compound were optimized by continually injecting standard solution with a syringe pump. The ESI conditions were set at optimum values to obtain acceptable sensitivity and selectivity for the compounds analyzed (Table S1 in Supplemental material). Among all the fragmented product ions, only two characteristic ions were performed in the MRM monitoring system. The most intensive fragment ion was used for quantification and the less intensive was used for qualification to avoid possible misidentification in the matrix (Table S1 in Supplemental material).

The gradient separation and the HPLC conditions were performed by three chromatographic columns (Capcell PAK C18, Agilent XDB C18 and Waters XBridge C18) using a mixed standard solution carried by different mobile phases as well as mobile phase additive (formic acid or ammonium acetate). Operational parameters and mobile phase additives were optimized frequently by adjustment and comparison to increase sensitivity and reduce signal suppression for each compound. This information also can be found in Table S1 (Supplemental material).

\subsection{Predicted concentrations of pharmaceuticals in sewage sludge}

The calculation procedures for predicted concentrations in sewage sludge $\left(C_{\text {sludges }}\right)$ was carried out for the studied compounds using the following equations as described by Stuer-Lauridsen 


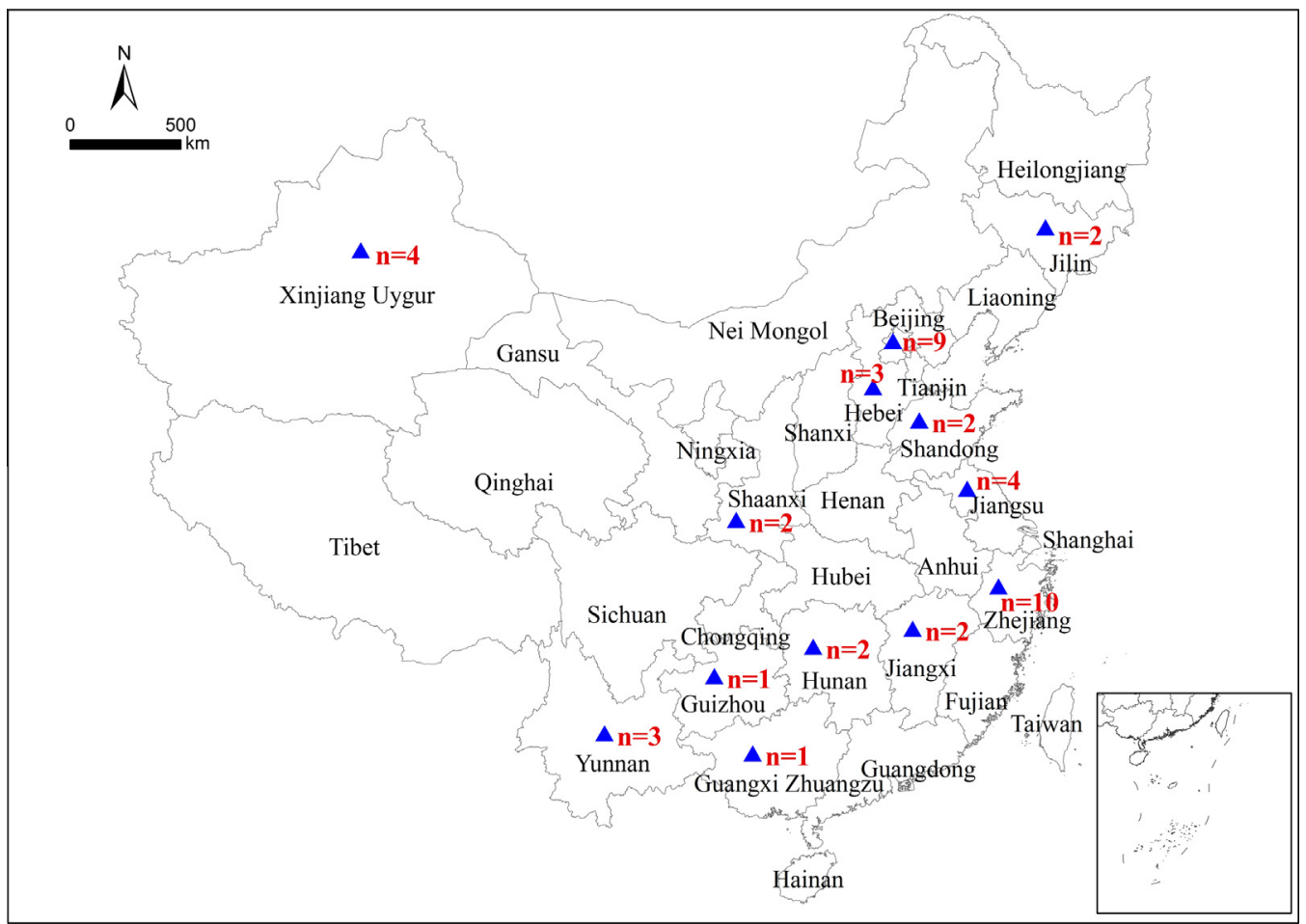

Fig. 1. Sewage sludge samples collected in different regions in China ( $n$ denotes the number of sampled STPs).
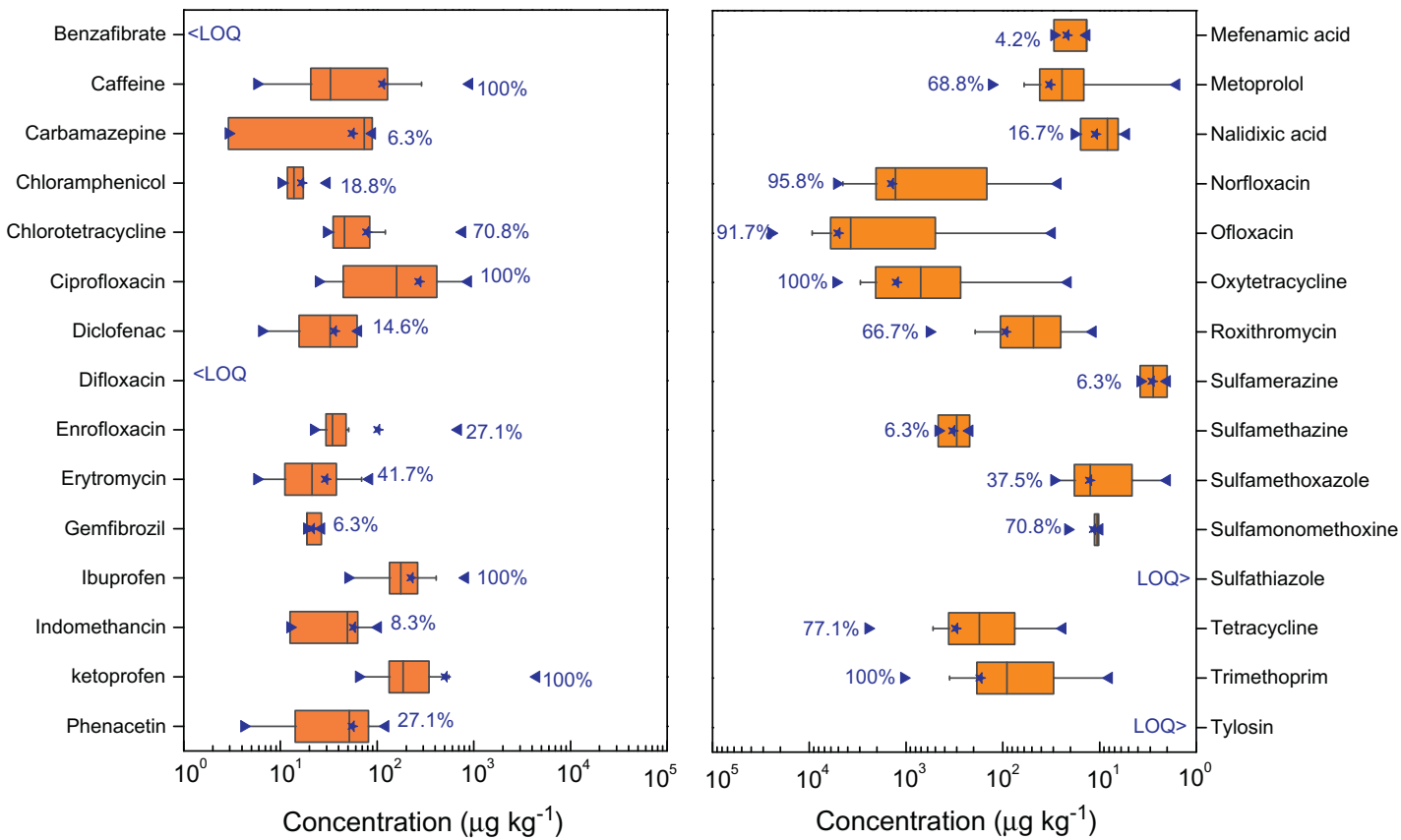

Fig. 2. Occurrence of the selected pharmaceuticals in sludge. Data beside each box denotes the frequency of detection in 45 sludge samples.

et al. (2000) and Grung et al. (2008). No degradation or other loss of the pharmaceuticals was assumed:

$\log K_{d}=f_{o c} \times 0.41 \times \log K_{o w}$

$C_{\text {sludge }}=\frac{M_{c}}{\frac{V_{w}}{K_{d}}+M_{s}}$ where the $K_{d}$ is the coefficient of sludge water partition, $\mathrm{L} \mathrm{kg}^{-1}$; $f_{o c}$ is the fraction of organic carbon in sludge, assumed to be 0.35 according to Stuer-Lauridsen et al. (2000) and Grung et al. (2008); $K_{o w}$ is the octanol/water partition coefficient; $M_{c}$ is the annual consumption of the compound $(\mathrm{kg})$ in China, calculated by subtracting the annual yield from annual amount exported with the value obtained from the Chinese Medical Statistical Yearbook; $V_{w}$ is total 
wastewater volume $\left(\mathrm{m}^{3}\right)$ in China in 2011 and, $M_{s}$ is the total sludge production $(\mathrm{kg})$ in China in 2011. Estimated data for $V_{w}$ and $M_{s}$ can be obtained from China City Statistical Yearbook (2012).

\section{6. $Q A / Q C$}

The reagent blanks were prepared from quartz sand in the laboratory and processed like the sewage sludge samples and the concentrations of the target compounds were below the limits of quantification (LOQ). Due to high matrix effects during the analytical procedure, the absolute recoveries (calculated by comparison between the concentrations of target compounds in spiked and unspiked sludge) for most compounds were poor (20.7-75.4\%). However, seven isotopically labeled compounds were used as internal standards to compensate the loss of most analytes, which led to good relative recoveries ranging from $66.6 \%$ to $132.5 \%$, except for oxytetracycline, norfloxacin and ofloxacin which showed extremely high recoveries (over 180\%). High residues of these
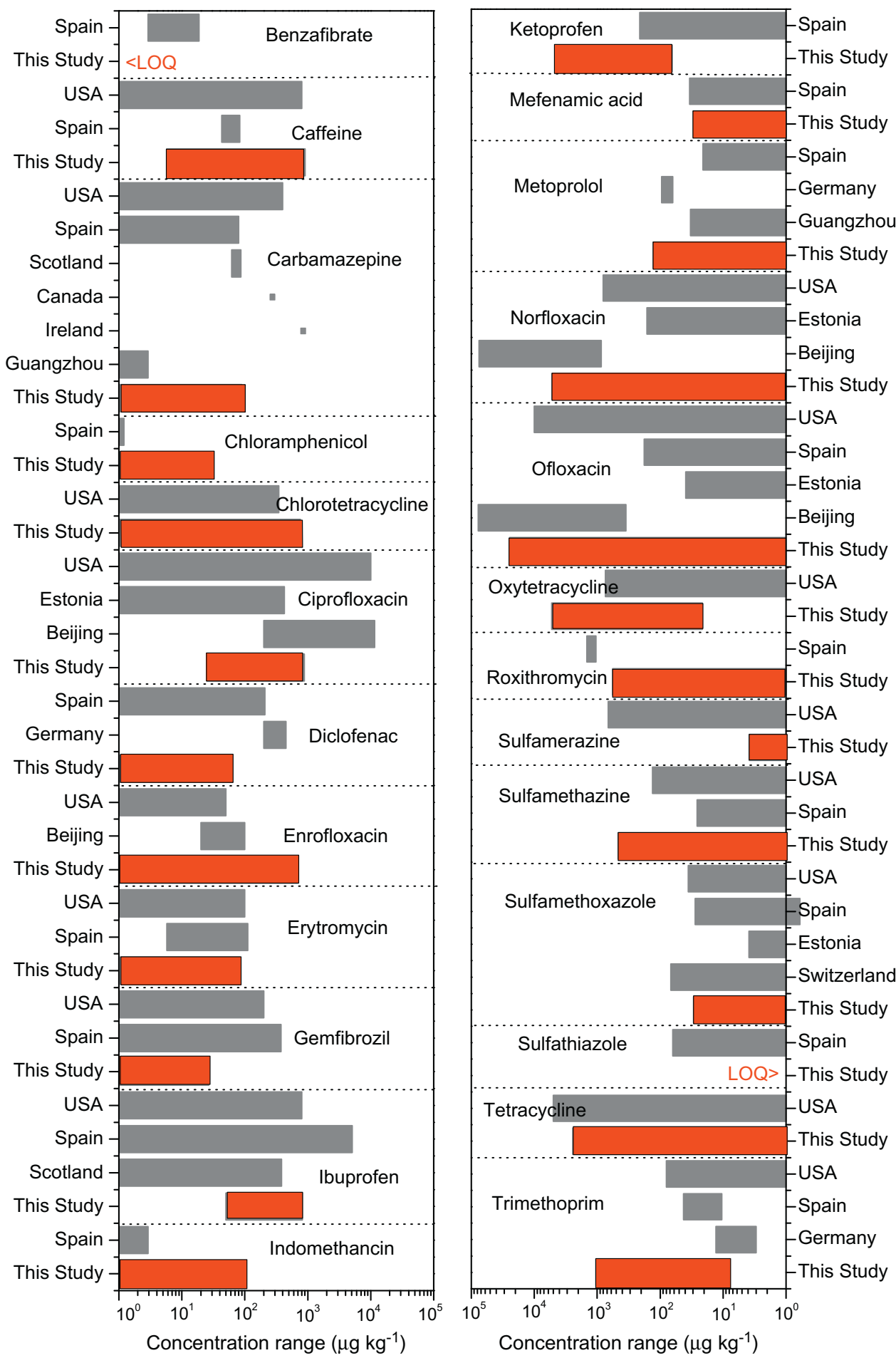

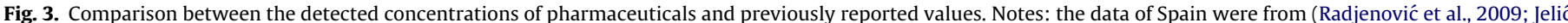

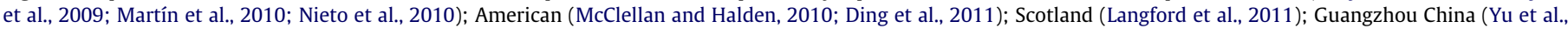

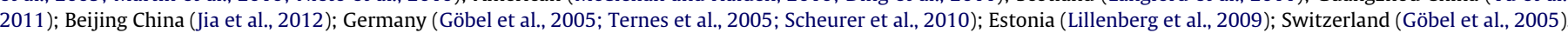




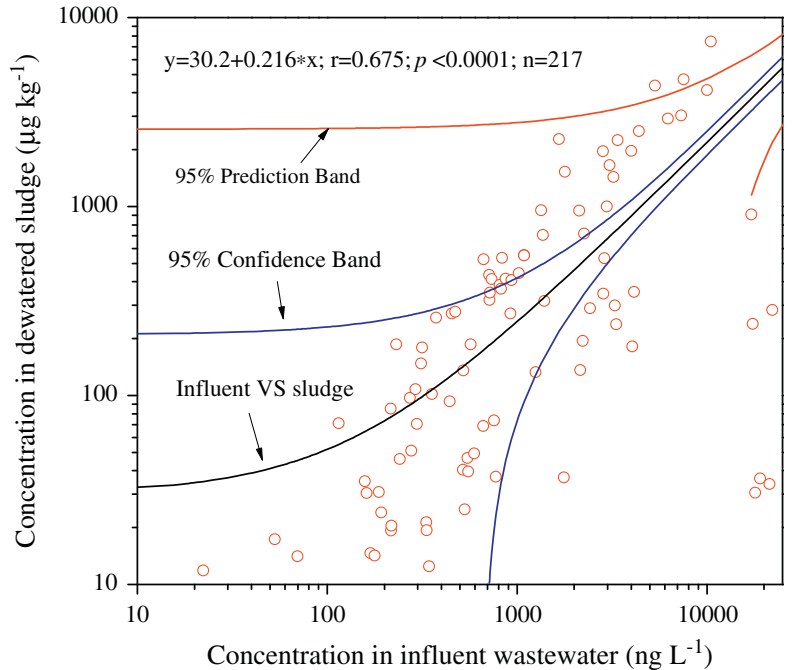

Fig. 4. The relationship between influent concentration and sludge concentration for investigated pharmaceuticals from 7 STPs in Beijing, China.

target compounds in the spiked samples were responsible for the high recoveries. Since the results for these pharmaceuticals in quartz sand matrix and other tetracyclines and fluoroquinolone antibiotics (e.g., chlortetracycline, ciprofloxacin, enrofloxacin) in the sludge matrix were satisfactory, the quality of the analytic procedure for oxytetracycline, norfloxacin and ofloxacin can also be assured. Each sample was spiked with two surrogates (D7-DEET and D5-atrazine) and aged overnight before sample extraction to ensure high quality of the extraction procedure. Detailed information on the calibration, recoveries, LOQ, and matrix effects was described elsewhere (Chen et al., 2012b) and summarized in Table S1 (Supplemental material).

\section{Results and discussion}

\subsection{Occurrence of pharmaceuticals}

The spatial concentrations of the pharmaceuticals investigated in the sewage sludge samples collected from 45 sewage treatment plants in China were provided in Fig. 2. The anti-infection (fluoroquinolone and tetracycline antibiotics) and anti-inflammatory (i.e., ketoprofen and ibuprofen) therapeutic groups were the dominant contaminants with high concentrations and frequencies of detection. For individual compounds, ofloxacin $\left(24760 \mu \mathrm{g} \mathrm{kg}^{-1}\right)$ was found to be the dominant compound, followed by oxytetracycline $\left(5280 \mu \mathrm{g} \mathrm{kg}^{-1}\right)$, norfloxacin $\left(5280 \mu \mathrm{g} \mathrm{kg}^{-1}\right)$ and ketoprofen $\left(4458 \mu \mathrm{g} \mathrm{kg}^{-1}\right)$. The occurrence of these pharmaceutical compounds in sewage sludge could be linked to their wide use in human medication. Another possible explanation is that these commonly occurring compounds with high concentrations in wastewaters (Sui et al., 2010; Zhou et al., 2010), can transport from the aqueous phase to the sludge during the dewatering and freezedrying process. Restricted use of chloramphenicol might explain its low presence in the collected sludge samples (Hirsch et al., 1999).

Table 1

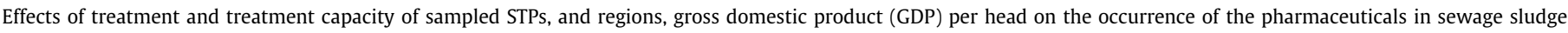
tested by two-way ANOVA and multiple comparisons (Tukey's HSD).

\begin{tabular}{|c|c|c|c|c|c|c|c|c|c|c|c|c|c|c|c|c|c|c|}
\hline Effect & Compound $^{\mathrm{a}}$ & $\mathrm{CPC}$ & CTC & CFC & EFC & GFZ & KPF & MFA & MPL & NLA & NFC & OFC & OTC & RTM & SMZ & SMX & TC & TP \\
\hline \multirow{7}{*}{$\begin{array}{l}\text { Treatment } \\
\text { technology }^{\mathrm{b}}\end{array}$} & $F$ value & 0.91 & 3.47 & 1.03 & 0.61 & 0.45 & 0.89 & 2.57 & 0.29 & 0.49 & 1.21 & 0.47 & 1.74 & 0.61 & 7.19 & 0.80 & 0.91 & 1.48 \\
\hline & $P$ & 0.45 & 0.02 & 0.39 & 0.61 & 0.72 & 0.45 & 0.07 & 0.83 & 0.69 & 0.32 & 0.7 & 0.17 & 0.61 & $<0.01$ & 0.50 & 0.44 & 0.24 \\
\hline & \multicolumn{18}{|c|}{ Multiple comparison (Tukey's HSD) } \\
\hline & $\mathrm{A} / \mathrm{A} / \mathrm{O}$ & & $\mathrm{A}^{\mathrm{c}}$ & & & & & & & & & & & & A & & & \\
\hline & $\mathrm{A} / \mathrm{O}$ & & $\mathrm{B}$ & & & & & & & & & & & & $\mathrm{B}$ & & & \\
\hline & SBR(CAST) & & $\mathrm{AB}$ & & & & & & & & & & & & A & & & \\
\hline & OD & & A & & & & & & & & & & & & A & & & \\
\hline \multirow{6}{*}{$\begin{array}{l}\text { Treatment capacity } \\
\qquad\left(\times 10^{3} \mathrm{~m}^{3}\right)\end{array}$} & $F$ value & 0.31 & 0.41 & 0.50 & 6.34 & 1.09 & 0.36 & 1.02 & 0.61 & 1.32 & 0.00 & 0.01 & 0.15 & 1.03 & 2.26 & 1.21 & 0.31 & 0.11 \\
\hline & $P$ & 0.73 & 0.67 & 0.61 & $<0.01$ & 0.35 & 0.7 & 0.37 & 0.55 & 0.28 & 1.00 & 0.99 & 0.86 & 0.36 & 0.12 & 0.31 & 0.74 & 0.90 \\
\hline & \multicolumn{18}{|c|}{ Multiple comparison (Tukey's HSD) } \\
\hline & $<100$ & & & & A & & & & & & & & & & & & & \\
\hline & $100-300$ & & & & A & & & & & & & & & & & & & \\
\hline & $>300$ & & & & B & & & & & & & & & & & & & \\
\hline \multirow[t]{9}{*}{ Regions $^{d}$} & $F$ value & 1.39 & 1.7 & 8.93 & 0.69 & 3.58 & 1.43 & 4.90 & 3.02 & 2.88 & 3.85 & 3.94 & 4.59 & 5.55 & 1.82 & 2.56 & 3.97 & 7.11 \\
\hline & $P$ & 0.26 & 0.18 & $<0.01$ & 0.56 & 0.02 & 0.25 & 0.01 & 0.04 & 0.05 & 0.02 & 0.01 & 0.01 & $<0.01$ & 0.16 & 0.07 & 0.01 & $<0.01$ \\
\hline & \multicolumn{18}{|c|}{ Multiple comparison (Tukey's HSD) } \\
\hline & East China & & & A & & $\mathrm{AB}$ & & A & A & $\mathrm{AB}$ & A & A & A & A & & & A & A \\
\hline & North & & & $\mathrm{B}$ & & A & & A & $\mathrm{B}$ & $\mathrm{AB}$ & B & $\mathrm{B}$ & B & A & & & $\mathrm{AB}$ & A \\
\hline & China & & & & & & & & & & & & & & & & & \\
\hline & South & & & B & & A & & A & $\mathrm{AB}$ & A & $\mathrm{AB}$ & $\mathrm{AB}$ & B & $\mathrm{AB}$ & & & $\mathrm{AB}$ & $\mathrm{AB}$ \\
\hline & China & & & & & & & & & & & & & & & & & \\
\hline & West China & & & $\mathrm{AB}$ & & B & & B & $\mathrm{AB}$ & B & $\mathrm{AB}$ & $\mathrm{AB}$ & B & B & & & B & B \\
\hline \multirow[t]{6}{*}{$\mathrm{GDP}^{\mathrm{e}}\left(\times 10^{3} \mathrm{RMB}\right)$} & $F$ value & 4.03 & 8.45 & 0.51 & 0.16 & 0.32 & 3.55 & 27.62 & 0.26 & 0.84 & 3.73 & 0.2 & 5.65 & 1.03 & 1.85 & 3.73 & 29.4 & 0.67 \\
\hline & $P$ & 0.03 & $<0.01$ & 0.60 & 0.86 & 0.73 & 0.04 & $<0.01$ & 0.77 & 0.44 & 0.03 & 0.82 & 0.01 & 0.37 & 0.17 & 0.03 & $<0.01$ & 0.52 \\
\hline & \multicolumn{18}{|c|}{ Multiple comparison (Tukey's HSD) } \\
\hline & $<30$ & A & A & & & & $\mathrm{AB}$ & A & & & A & & A & & & $\mathrm{AB}$ & A & \\
\hline & $30-60$ & B & B & & & & A & B & & & $\mathrm{AB}$ & & B & & & A & B & \\
\hline & $>60$ & B & B & & & & B & B & & & B & & B & & & B & B & \\
\hline
\end{tabular}

a Only the compounds at significant differences were presented, i.e., chloramphenicol (CPC), chlorotetracycline (CTC), ciprofloxacin (CFC), enrofloxacin (EFC), gemfibrozil

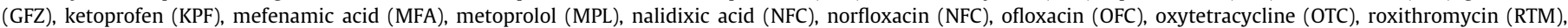
sulfamethazine (SMZ), sulfamethoxazole (SMX), tetracycline (TC), and trimethoprim (TP).

b A/A/O denotes anaerobic/anoxic/oxic activated sludge process; A/O denotes anoxic/oxic activated sludge process; OD denotes oxidation ditch; SBR denotes sequencing batch reactor activated sludge process; CAST denotes cyclic activated sludge technology, which is modified from SBR.

${ }^{c}$ Different letters represent differences among treatment technology and treatment capacity are significant at $p<0.05$.

d East china includes the sampled area of Shangdong, Jiangsu, Zhejiang in Fig. 1; North China includes the sampled area of Beijing, Jilin, Hebei in Fig. 1; South China includes the sampled area of Hunan, Jiangxi, Guangxi Zhuangzu, Guizhou, Yunnan in Fig. 1; West China includes the sampled area of Xinjiang Uygur, Shaanxi in Fig. 1.

e GDP per head was collected from the statistical bulletin of national economic and social development (2012) for each sampled city. 
Difloxacin and tylosin were below detection limits because their uses are only restricted to animal husbandry (Li et al., 2012), resulting in a low concentrations in the agricultural wastewater loaded into the sewage treatment plants. Moreover, the chemical properties of pharmaceuticals also affect their presence in sewage sludge. For example, sulfonamide antibiotics were found at lower detectable levels which could be attributed to their weak adsorption capacity and persistent tendency to remain in the aqueous environment (Chen et al., 2012c), while the low occurrence of other compounds may be due to their ready dissipation under current treatment processes and in addition to their low loading rates into wastewater systems (Bueno et al., 2012).

Several studies have been investigated the concentrations of pharmaceuticals in sewage sludge and the reported contamination levels vary substantially among different regions. A comparison of the contamination patterns of pharmaceuticals in sewage sludge reported in previous studies was given in Fig. 3. The detectable concentrations of pharmaceuticals in China were at a similar order of magnitude to those previously reported in other countries. Antibiotics such as ofloxacin, norfloxacin, ciprofloxacin, oxytetracycline and trimethoprim showed relatively higher contamination levels than those reported in developed counties, while the therapeutic compounds such as benzafibrate and gemfibrozil used for cardiovascular and hematological therapy were lower. The concentrations of indomethancin and ketoprofen used for antipyretic and analgesic applications were also present in higher concentrations than those in Spain. The differences in the contamination patterns can be explained by the differences in prescription practices related to the level of economic development and healthcare. Generally, developing countries need more antibiotics to control infectious diseases and injuries due to their poorly developed healthcare systems (Istúriz and Carbon, 2000). In contrast, developed countries need more antilipidemic and anti-hypertensive medicines for cardiovascular and hematological conditions. On the other hand, developing countries have less wastewater treatment plants per capita, which may result in low dissipation rates of pharmaceuticals in sewage systems. Moreover, the considerable presence of caffeine in the sewage sludge might also reflect its wide consumption and excessive dosage.
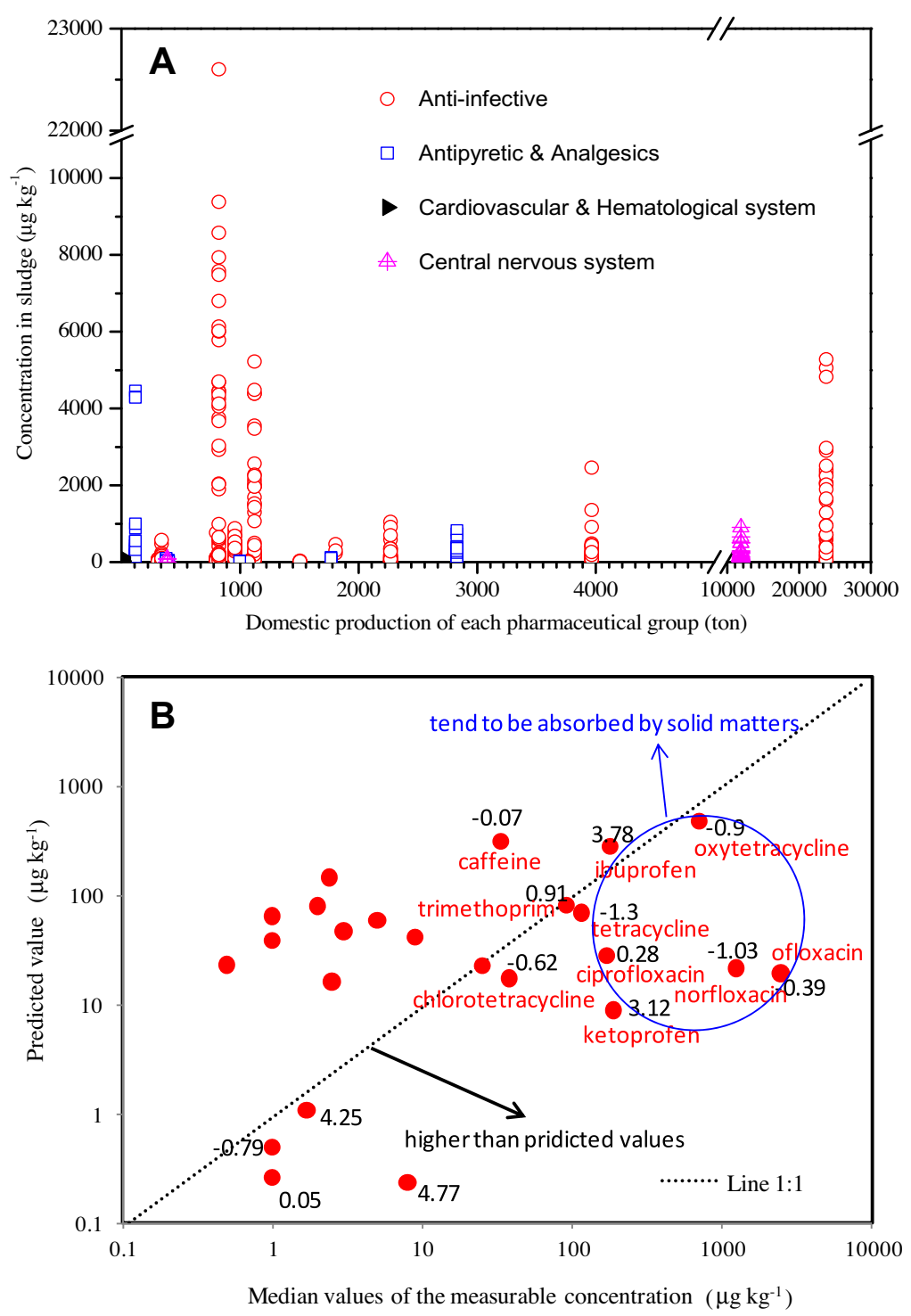

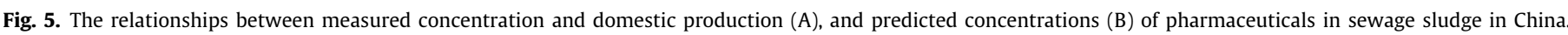

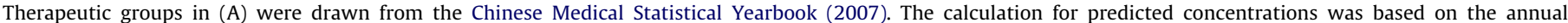

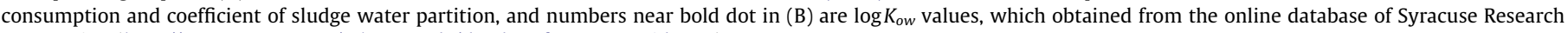
Corporation (http://www.syrres.com/what-we-do/databaseforms.aspx?id=386). 


\subsection{Factors affecting the presence of pharmaceuticals}

The relationship between the concentrations of pharmaceuticals with different factors affecting their presence in sewage sludge was presented in Fig. 4. A positive significant correlation was found between the concentrations of pharmaceuticals in sewage sludge and wastewater samples. The large amounts of pharmaceuticals (Fig. 2) might be due to their widespread uses in human health sector, while the lower concentrations of compounds in sewage sludge could be due to their less use. Treatment rates of wastewaters may also affect the presence of pharmaceuticals in sewage sludge because high rates of transformation and removal of pharmaceuticals might occur in sewage treatment processes (Sui et al., 2010; Jelic et al., 2011). However, statistical analysis (Table 1) shows that most of the measurable pharmaceutical compounds have no significant difference except for chlorotetracycline and sulfamethazine in comparison with the treatment technology and enrofloxacin in comparison with the treatment capacity. These various associations may be explained by the fact that pharmaceuticals varies significantly in physicochemical properties and may interact with particular matter of dissolved organic matter or activated sludge under suitable conditions (Ternes et al., 2004; Carballa et al., 2008). Similar results showing rough relationships between the presence of anthropogenic pollutants and basic characteristics of wastewater treatment systems have been found in other treatment plants (Batt et al., 2007; Wang et al., 2007), indicating that the presence of contaminants in sludge is likely to be dictated by high variability of chemical and wastewater properties. This high variability may affect the dissipation, absorption and sedimentation of pharmaceutical compounds in wastewaters (Ternes et al., 2004; Carballa et al., 2008). In addition, biological treatment such as activated sludge often fails to degrade antibiotic compounds, resulting in high residues of these therapeutic compounds in sewage sludge (Kim et al., 2005; Batt et al., 2007). In this study, most of the pharmaceutical compounds showed significant variation among the different sampling regions. The presence of pharmaceuticals in sludge from East China was significantly different from those in North or West China (Table 1), indicating differences in prescription practices for healthcare. The different regional climate presents an additional factor affecting the presence of individual compounds in sewage sludge, as temperature plays a key role controlling their sorption or degradation processes (Fernandez-Fontaina et al., 2012). Family income may also exert some influences on the presence of some pharmaceuticals in sewage sludge (Table 1 ) by different consumption pattern of medicines and investment in sewage treatment plants (Zhang et al., 2008).

\subsection{Dominant therapeutic groups and their predicted fate}

Different therapeutic groups observed in sewage sludge samples and their predicted fate in sewage sludge in China was shown in Fig. 5. Anti-infection chemicals were the dominant group followed by the antipyretic and analgesic. The other groups such as those used for central nervous system, cardiovascular and hematological systems were at lower levels. The domestic production of each compound showed no detectable correlations with their concentrations present in sludge (Fig. 5A), indicating that pharmaceutical residues in sewage sludge may be determined by physicochemical properties of compound, types of wastewater and the loading rates. In this study, pharmaceuticals (gemfibrozil and metoprolol) targeting the cardiovascular and hematological systems have shown high degradation rates in sewage treatment plants (Bueno et al., 2012), resulting low concentrations of these compounds in sewage sludge. To calculate pharmaceutical concentrations in sewage sludge on a national scale, Eqs. (1) and (2) were used (Stuer-Lauridsen et al., 2000; Grung et al., 2008). The absence of any correlation between the occurrence of pharmaceuticals and their predicted concentrations was explained by high variability of the compound properties and operation conditions of sewage treatment plants (Fig. 5B). Fluoroquinolone and tetracycline antibiotics have a considerable sorption tendency into sewage sludge as a result of electrostatic interactions with suspended materials (Prado et al., 2009; Speltini et al., 2011), which may lead to their high concentrations. The octanol-water partitioning coefficient $\left(K_{o w}\right)$ may also determine their affinity with suspended solids, particularly for hydrophobic pharmaceuticals (Chiaia-Hernandez et al., 2012). However, large discrepancies for pharmaceuticals with high $K_{o w}$ values were also reported (Ternes et al., 2004; Carballa et al., 2008). The polar functional groups such as carboxylic moieties, aldehydes and amines may interact only with special parts of organic materials or minerals (Carballa et al., 2008). The polarity of the functional groups of pharmaceutical compounds should be considered in future studies to predict their fate in municipal wastewater systems. Moreover, a lack of accurate data on medicine prescription and direct discharge of hospital wastewater into sewage system may also contribute to the poor relationships between the predicted and detected pharmaceuticals in developing countries.

\section{Conclusions}

It can be concluded that anti-infection pharmaceuticals (fluoroquinolone and tetracycline antibiotics) and antipyretic and analgesic pharmaceuticals (ketoprofen and ibuprofen) were thedominant groups found in sewage sludge collected from 45 sewage treatment plants in China. These compounds were presented at higher concentrations than those reported previously in developed countries, indicating their wide use in China. The physicochemical properties of pharmaceuticals, their loading rates and the wastewater characteristics were combined to contribute to their different distribution pattern in sewage sludge. As a result, poor correlations between the detected and predicted concentrations in sewage sludge have been observed. Future studies are needed to predict the actual fate of pharmaceuticals in municipal wastewater systems as well as their environmental effects in sewage sludge. i.

\section{Acknowledgments}

This work was financially supported by National Natural Science Foundation of China (No. 41006064); Tsinghua University - Veolia Environment Joint Research Center for Advanced Environmental Technology; and Fujian Provincial Natural Science Foundation of China (No. 2012J05081). We also thank Dr. Peter Christie, from Agri-Environment Branch, Agri-Food and Biosciences Institute in UK; and Dr. Sardar Khan, from Department of Environmental Sciences, University of Peshawar in Pakistan for their kind helps in language polishing.

\section{Appendix A. Supplementary material}

Supplementary data associated with this article can be found, in the online version, at http://dx.doi.org/10.1016/j.chemosphere. 2013.06.007.

\section{References}

Bailly, E., Levi, Y., Karolak, S., 2013. Calibration and field evaluation of polar organic chemical integrative sampler (POCIS) for monitoring pharmaceuticals in hospital wastewater. Environ. Pollut. 174, 100-105.

Batt, A.L., Kim, S., Aga, D.S., 2007. Comparison of the occurrence of antibiotics in four full-scale wastewater treatment plants with varying designs and operations. Chemosphere 68, 428-435. 
Bueno, M.J., Gomez, M.J., Herrera, S., Hernando, M.D., Agüera, A., Fernández-Alba, A.R., 2012. Occurrence and persistence of organic emerging contaminants and priority pollutants in five sewage treatment plants of Spain: two years pilot survey monitoring. Environ. Pollut. 164, 267-273.

Carballa, M., Fink, G., Omil, F., Lema, J.M., Ternes, T., 2008. Determination of the solid-water distribution coefficient $(\mathrm{Kd})$ for pharmaceuticals, estrogens and musk fragrances in digested sludge. Water Res. 42, 287-295.

Chen, H., Yan, S.H., Ye, Z.L., Meng, H.J., Zhu, Y.G., 2012a. Utilization of urban sewage sludge: Chinese perspectives. Environ. Sci. Pollut. Res. 19, 1454-1463.

Chen, Y.S., Cao, Q.M., Deng, S.B., Huang, J., Wang, B., Yu, G., 2012b. Determination of pharmaceuticals from various therapeutic classes in dewatered sludge by pressurized liquid extraction coupled with high performance liquid chromatography and tandem mass spectrometry (HPLC-MS/MS). Int. J. Environ. Anal. Chem. http://dx.doi.org/10.1080/03067319.2012.717271.

Chen, Y.S., Zhang, H.B., Song, J., Luo, Y.M., 2012c. Occurrence and dissipation of veterinary antibiotics in two typical swine wastewater treatment systems in east China. Environ. Monit. Assess. 184, 2205-2217.

Chiaia-Hernandez, A.C., Krauss, M., Hollender, J., 2012. Screening of lake sediments for emerging contaminants by liquid chromatography atmospheric pressure photoionization and electrospray ionization coupled to high resolution mass spectrometry. Environ. Sci. Technol. http://dx.doi.org/10.1021/es303888.

China Bureau of Statistics, 2012. China City Statistical Yearbook 2012. China Statistics Press.

China Medicine Economic Information Net (CMEIN), 2007. Chinese Medical Statistical Yearbook (2006-2007). China Medicine Economic Information Net, Beijing, China.

Daughton, C.G., Ternes, T.A., 1999. Pharmaceuticals and personal care products in the environment: agents of subtle change? Environ. Health Perspect. 107 (S6), 907-938.

Ding, Y., Zhang, W., Gu, C., Xagoraraki, I., Li, H., 2011. Determination of pharmaceuticals in biosolids using accelerated solvent extraction and liquid chromatography/tandem mass spectrometry. J. Chromatogr. A 1218, 10-16.

Ellis, J.B., 2006. Pharmaceutical and personal care products (PPCPs) in urban receiving waters. Environ. Pollut. 144, 184-189.

Fernandez-Fontaina, E., Pinho, I., Carballa, M., Omil, F., Lema, J.M., 2012. Biodegradation kinetic constants and sorption coefficients of micropollutants in membrane bioreactors. Biodegradation. http://dx.doi.org/10.1007/s10532012-9568-3.

Gao, P., Munir, M., Xagoraraki, I., 2012. Correlation of tetracycline and sulfonamide antibiotics with corresponding resistance genes and resistant bacteria in a conventional municipal wastewater treatment plant. Sci. Total Environ., 173183.

Göbel, A., Thomsen, A., McArdell, C.S., Joss, A., Giger, W., 2005. Occurrence and sorption behavior of sulfonamides, macrolides, and trimethoprim in activated sludge treatment. Environ. Sci. Technol. 39, 3981-3989.

Grung, M., Källqvist, T., Sakshaug, S., Skurtveit, S., Thomas, K.V., 2008. Environmental assessment of Norwegian priority pharmaceuticals based on the EMEA guideline. Ecotoxicol. Environ. Saf. 71, 328-340.

Hirsch, R., Ternes, T., Haberer, K., Kratz, K.L., 1999. Occurrence of antibiotics in the aquatic environment. Sci. Total Environ. 225, 109-118.

Istúriz, R.E., Carbon, C., 2000. Antibiotic use in developing countries. Infect. Control Hosp. Epidemiol. 21, 394-397.

Jelić, A., Petrović, M., Barceló, D., 2009. Multi-residue method for trace level determination of pharmaceuticals in solid samples using pressurized liquid extraction followed by liquid chromatography/quadrupole-linear ion trap mass spectrometry. Talanta $80,363-371$.

Jelic, A., Gros, M., Ginebreda, A., Cespedes-Sánchez, R., Ventura, F., Petrovic, M. Barcelo, D., 2011. Occurrence, partition and removal of pharmaceuticals in sewage water and sludge during wastewater treatment. Water Res. 45, 11651176.

Jia, A., Wan, Y., Xiao, Y., Hu, J., 2012. Occurrence and fate of quinolone and fluoroquinolone antibiotics in a municipal sewage treatment plant. Water Res. 46, 387-394.

Kaplan, S., 2012. Review: pharmacological pollution in water. Crit. Rev. Environ. Sci. Technol. http://dx.doi.org/10.1080/10934529.2011.627036.

Kelessidis, A., Stasinakis, A.S., 2012. Comparative study of the methods used for treatment and final disposal of sewage sludge in European countries. Waste Manage. 32, 1186-1195.

Kim, S., Eichhorn, P., Jensen, J.N., Weber, A.S., Aga, D.S., 2005. Removal of antibiotics in wastewater: effect of hydraulic and solid retention times on the fate of tetracycline in the activated sludge process. Environ. Sci. Technol. 39, 58165823.

Kolpin, D.W., Furlong, E.T., Meyer, M.T., Thurman, E.M., Zaugg, S.D., Barber, L.B., Buxton, H.T., 2002. Pharmaceuticals, hormones, and other organic wastewater contaminants in US streams, 1999-2000: a national reconnaissance. Environ. Sci. Technol. 36, 1202-1211.

Kristiansson, E., Fick, J., Janzon, A., Grabic, R., Rutgersson, C., Weijdegård, B., Söderström, H., Larsson, D.G., 2011. Pyrosequencing of antibiotic-contaminated river sediments reveals high levels of resistance and gene transfer elements. PLoS One 6, e17038.

Kümmerer, K., 2009. The presence of pharmaceuticals in the environment due to human use - present knowledge and future challenges. J. Environ. Manage. 90, 2354-2366.
Langford, K.H., Reid, M., Thomas, K.V., 2011. Multi-residue screening of prioritised human pharmaceuticals, illicit drugs and bactericides in sediments and sludge. J. Environ. Monit. 13, 2284-2291.

Lee, W., Kang, C.W., Su, C.K., Okubo, K., Nagahama, Y., 2012. Screening estrogenic activity of environmental contaminants and water samples using a transgenic medaka embryo bioassay. Chemosphere 88, 945-952.

Li, Y.X., Zhang, X.L., Li, W., Lu, X.F., Liu, B., Wang, J., 2012. The residues and environmental risks of multiple veterinary antibiotics in animal faeces. Environ. Monit. Assess. http://dx.doi.org/10.1007/s10661-012-2702-1.

Lillenberg, M., Yurchenko, S., Kipper, K., Herodes, K., Pihl, V., Sepp, K., Lõhmus, R., Nei, L., 2009. Simultaneous determination of fluoroquinolones, sulfonamides and tetracyclines in sewage sludge by pressurized liquid extraction and liquid chromatography electrospray ionization-mass spectrometry. J. Chromatogr. A 1216, 5949-5954.

Martín, J., Santos, J.L., Aparicio, I., Alonso, E., 2010. Multi-residue method for the analysis of pharmaceutical compounds in sewage sludge, compost and sediments by sonication-assisted extraction and LC determination. J. Sep. Sci. 33, 1760-1766.

Martín, J., Camacho-Muñoz, D., Santos, J.L., Aparicio, I., Alonso, E., 2012a. Occurrence of pharmaceutical compounds in wastewater and sludge from wastewater treatment plants: removal and ecotoxicological impact of wastewater discharges and sludge disposal. J. Hazard. Mater. 239-340, 40-47.

Martín, J., Camacho-Muñoz, M.A., Santos, J.L., Aparicio, I., Alonso, E., 2012b. Distribution and temporal evolution of pharmaceutically active compounds alongside sewage sludge treatment. Risk assessment of sludge application onto soils. J. Environ. Manage. 102, 18-25.

McClellan, K., Halden, R.U., 2010. Pharmaceuticals and personal care products in archived US biosolids from the 2001 EPA National Sewage Sludge Survey. Water Res. 44, 658-668.

Miao, X.S., Yang, J.J., Metcalfe, C.D., 2005. Carbamazepine and its metabolites in wastewater and in biosolids in a municipal wastewater treatment plant. Environ. Sci. Technol. 39, 7469-7475.

Nieto, A., Borrull, F., Pocurull, E., Marc, R.M., 2007. Pressurized liquid extraction of pharmaceuticals from sewage-sludge. J. Sep. Sci. 30, 979-984.

Nieto, A., Borrull, F., Pocurull, E., Marcé, R.M., 2010. Occurrence of pharmaceuticals and hormones in sewage sludge. Environ. Toxicol. Chem. 29, 1484-1489.

Ort, C., Lawrence, M.G., Rieckermann, J., Joss, A., 2010. Sampling for pharmaceuticals and personal care products (PPCPs) and illicit drugs in wastewater systems: are your conclusions valid? A critical review. Environ. Sci. Technol. 44, 6024-6035.

Prado, N., Ochoa, J., Amrane, A., 2009. Biodegradation and biosorption of tetracycline and tylosin antibiotics in activated sludge system. Process Biochem. 44, 1302-1306.

Radjenović, J., Jelić, A., Petrović, M., Barceló, D., 2009. Determination of pharmaceuticals in sewage sludge by pressurized liquid extraction (PLE) coupled to liquid chromatography-tandem mass spectrometry (LC-MS/MS). Anal. Bioanal. Chem. 393, 1685-1695.

Scheurer, M., Ramil, M., Metcalfe, C.D., Groh, S., Ternes, T.A., 2010. The challenge of analyzing beta-blocker drugs in sludge and wastewater. Anal. Bioanal. Chem. 396, 845-856.

Speltini, A., Sturini, M., Maraschi, F., Profumo, A., Albini, A., 2011. Analytical methods for the determination of fluoroquinolones in solid environmental matrices. TrAC Trends Anal. Chem. 30, 1337-1350.

Stuer-Lauridsen, F., Birkved, M., Hansen, L.P., Lützhøft, H.C., Halling-Sørensen, B. 2000. Environmental risk assessment of human pharmaceuticals in Denmark after normal therapeutic use. Chemosphere 40, 783-793.

Sui, Q., Huang, J., Deng, S.B., Yu, G., Fan, Q., 2010. Occurrence and removal of pharmaceuticals, caffeine and DEET in wastewater treatment plants of Beijing, China. Water Res. 44, 417-426.

Ternes, T.A., Herrmann, N., Bonerz, M., Knacker, T., Siegrist, H., Joss, A., 2004. A rapid method to measure the solid-water distribution coefficient (Kd) for pharmaceuticals and musk fragrances in sewage sludge. Water Res. 38, 40754084.

Ternes, T.A., Bonerz, M., Herrmann, N., Löffler, D., Keller, E., Lacida, B.B., Alder, A.C. 2005. Determination of pharmaceuticals, iodinated contrast media and musk fragrances in sludge by LC/tandem MS and GC/MS. J. Chromatogr. A 1067, 213 223.

Wang, Y., Zhang, Q., Lv, J., Li, A., Liu, H., Li, G., Jiang, G., 2007. Polybrominated diphenyl ethers and organochlorine pesticides in sewage sludge of wastewater treatment plants in China. Chemosphere 68, 1682-1691.

Williams, E.S., Brooks, B.W., 2012. Human health risk assessment for pharmaceuticals in the environment: existing practice, uncertainty, and future directions. Hum. Pharm. Environ. (Emerging Topics in Ecotoxicology) 4, $167-224$

Yu, Y., Huang, Q., Cui, J., Zhang, K., Tang, C., Peng, X., 2011. Determination of pharmaceuticals, steroid hormones, and endocrine-disrupting personal care products in sewage sludge by ultra-high-performance liquid chromatographytandem mass spectrometry. Anal. Bioanal. Chem. 399, 891-902.

Zhang, Y., Geissen, S.U., Gal, C., 2008. Carbamazepine and diclofenac: removal in wastewater treatment plants and occurrence in water bodies. Chemosphere 73 1151-1161.

Zhou, H.D., Wu, C.Y., Huang, X., Gao, M.J., Wen, X.H., Tsuno, H., Tanaka, H., 2010 Occurrence of selected pharmaceuticals and caffeine in sewage treatment plant and receiving rivers in Beijing, China. Water Environ. Res. 82, 2239-2248. 